\title{
Description and Analysis of Adsorption Heat Storage Device
}

\author{
Uroš Stritih* - Andrej Bombač \\ University of Ljubljana, Faculty of Mechanical Engineering, Slovenia
}

In this study, the main goal was to develop an adsorption heat storage system for domestic heating system gained by solar collectors and to indicate a new way of maintaining the energy. Main characteristic of the storage system is to retain the energy for a longer period, as long as the adsorbent and adsorbat are separated. This research analysis the influence of several parameters on the adsorption heat storage system such as: the quantity of the stored heat, the in- and out-flowing water temperatures, the water mass flow and the saturation of the adsorbent. Adsorbent $\mathrm{HX}-13$ sodium aluminosilicate $\mathrm{Na}_{2} \mathrm{O} \mathrm{Al}_{2} \mathrm{O}_{3}$ * $2 \mathrm{SiO}_{2}$ in the form of granule was used.

Regarding the results we can be conclude that the low adsorption heat storage is low hydrophilic characteristic of the used adsorbent. Keywords: heat storage device, thermo-chemical heat storage, adsorbat, adsorbents, experiment

\section{O INTRODUCTION}

Increased use of energy, diminishing supplies of fossil fuels and concern for a better environment tends to exploit energy from renewable energy sources, among others e.g., gas accumulator in water hydraulic systems [1]. As a result, energy storage devices were developed. They store energy from natural sources (solar [2], geothermal) as well as industrial waste heat [3] that makes heat storage especially useful in industry, where lots of heating or chilling is needed [4]. Increasing emphasis is also given to heat storage systems for domestic heating and cooling [5] to [7]. Sorption technologies gained a lot of interests for solar heat storage of solar energy in recent years due to their high energy densities and long-term preservation ability for thermal energy [8]. Sorption heat storage device is based on the principle of thermo-chemical storage. Ongoing research and development studies show that the challenges of the technology focus on the aspects of different types of sorption materials [9] and [10], the configurations of absorption cycles and advanced adsorption reactors. Booming progress illustrates that sorption thermal storage is a realistic and sustainable option for storing solar heat energy, especially for long-term applications.

In the thermo-chemical energy storage methodology, sorption material and gas are chosen as the sorption working couple for energy storage, whereby thermal energy is stored in the form of chemical bonds resulting from the sorption process between the material and the gas [11]. The current state in the field of adsorptive heat transformation (AHT) cannot be considered as wholly satisfactory, due to inappropriate thermodynamic properties of adsorbent materials [12], so studies tend to improve materials. Developed composite sorbents made from active salts and porous materials showed improved sorption storage capacity when compared with waterbased energy storage due to its high energy density [13] to [15]. Exergy analysis performed by Abedin and Rosen [16] showed that thermo-chemical sorption energy storage system may be as efficient as and even more stable than other types of thermal energy storage system.

Restuccia et al. [17] presented the experimental results of a lab-scale chilling module working with the composite sorbent SWS-1L, which is a promising alternative to the common zeolite or silica gel, for application in solid sorption and compared experimental results with a theoretical simulation. Their approach was also used to study the influence of the main operating parameters on the system performance and to make recommendations on how to improve the chillers design and process parameters. Glaznev et al. [18] investigated how a gradual tuning of pore size affects the water sorption properties; composites with smaller pores are able to generate cold rejecting the adsorption heat to hotter environment. Stronger water bounding by the salt confined to smaller pores results in the appropriate enhancement of the desorption temperature. It was shown that the small, micro porous aluminophosphates are among the most suitable materials for low temperature (solar) heat storage.

In the last two decades, several studies propose different developed adsorption solar cooling systems which allow a good compromise between high reliability and good performance. From those studies, simple tubular module is considered as one of the most efficient configurations [19] and [20]. The adsorption tubular module is a tube in which an adsorber, a condenser and an evaporator are all completely housed to construct a small scale adsorption cooling unit. Heat pipes can also be used in adsorption refrigeration systems to improve the performance of 
the systems. Thermally driven adsorption chillers and heat pumps have received increased attention in recent years. Heat pumping devices which are operating on sorption effects, current trends and forthcoming applications were studied and discussed by Ziegler [21] and [22]. Henninger et al. [23] analysed current available active sorption materials (like silica gels and zeolites), recently developed materials (aluminophosphates) and silica-aluminophosphates (SAPO) as well as novel materials (like metal organic frameworks under continuous thermal cycling in a water vapor atmosphere) in order to evaluate their suitability for the use in a periodically working heat pump based on water as working fluid. Besides solar cooling application for thermal cooling using waste heat at low temperature level $\left(<80^{\circ} \mathrm{C}\right.$ for adsorption systems) the combination of co-generation units with sorption chiller is promising as described in [24]. While adsorption thermal storage systems are useful for long-term (seasonal) storage, systems with phase change materials (PCM's) are used for short-term (daily) storage [25] and [26].

The aim of this work is to present sorption thermal storage tank with HX13 which can be used for long term thermal energy storage. Parts of thermal storage, experimental results of adsorption and desorption, i.e. temperatures, heat fluxes and heat are presented and explained.

\section{THEORETICAL ANALYSIS}

Closed sorption system utilysing water used as the adsorbate [adsorptive], is shown in Fig. 1. During the process of desorption, adsorbent is connected and heated through the heat exchanger. Surface bounded adsorbate is evaporated from adsorbent and heat is transferred from the condenser. Desorption mode stops when the adsorbent is dried out (depends on the input heat amount in the adsorber), i.e. adsorbate is condensed in the condenser, or when the adsorbent and adsorbate are separated.

During the process of adsorption, adsorption heat has to be discharged from the adsorber and evaporation heat supplied into the evaporator. If this is not possible, sorption process reaches thermodynamic equilibrium and the flow of water vapour is stopped. When the adsorbent is saturated with water vapour, the process ends and the tank is discharged. It needs to be recharged again (desorption). Circular process of adsorption storage shown in Fig. 2 is the same as a circular process of a heat pump, except here is a 'time break' during the process of adsorption and desorption. This break is the time when the storage heat is not needed.

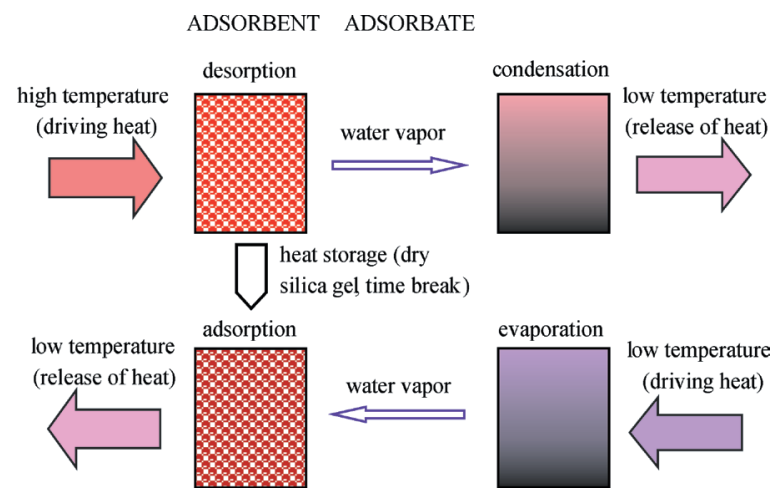

Fig. 1. Working principle of a closed-cycle desorption/adsorption heat storage

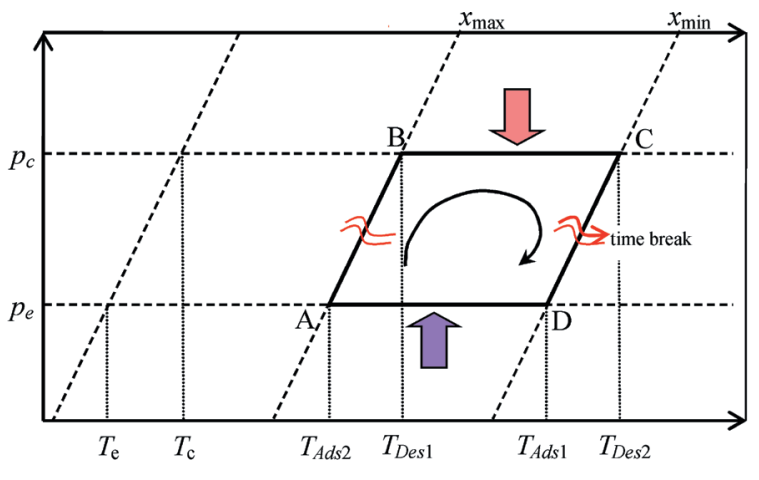

Fig. 2. $p-T-x$ diagram of thermochemical storage cycle

The adsorbed mass of the fluid (an adsorbate) varies between a minimum (line C-D) and the maximum value (line A-B). Adsorption takes place (between points D-A) at the evaporation pressure $p_{e}$ and desorption (between points B-C) at a pressure of condensation $p_{c}$ [5]. This four-step cycle consists of:

1. Heat storage in the tank begins with isosteric heating of the adsorbent (humidity is constant) through the heat exchanger. The valve that separates the tank from the evaporator/condenser is closed. The temperature and pressure in the adsorber are increasing along the line between points $\mathrm{A}$ and $\mathrm{B}$ as long as the temperature $T_{\text {des } 1}$ is reached. At this temperature, pressure is equal to the pressure of condensation of the adsorbed adsorbate (point B) [25].

2. At point $B$ the valve between the condenser and the adsorber is opened. Adsorbent is heated (the line between the points B-C) until the adsorbate is separated and the adsorbent is dry. Maximum available temperature $T_{\text {des } 2}$ is reached. Meanwhile condenser is cooled to maintain the pressure 
of condensation $p_{c}$. Heat generated by the condensation $Q_{c}$ is entrained into the environment as a waste heat. This influence on the temperature of condensation $T_{c}$, which must be kept as low as possible in order to make optimal desorption. At maximum attained temperature $T_{\mathrm{des} 2}$ the level of saturation of the adsorbent with adsorbate is the lowest $\left(x_{\min }\right)$, so cycle is stopped with the closure of the valve between condenser and adsorber. When the valve is closed - and the adsorbate and adsorbent are separated - the tank is filled. Thus, the stored energy can be used without loss, even after a longer period [27].

3. Depending on energy storage duration and ambient temperature, the temperature of the heat storage falls. Temperature drop and, consequently, the pressure drop are shown with isostera, line between points $\mathrm{C}$ and $\mathrm{D}$. The temperature may drop to $T_{\text {ads1 }}$ or even lower [27].

4. Discharging begins with the opening of the valve that separates the evaporator from the adsorber. Before that a higher pressure level in the evaporator than in the adsorber is established, because of the added heat. Heat can be provided from a variety of sources (solar, earth, etc.). Liquid is evaporated at a pressure $p_{e}$ and temperature $T_{e}$. The valve opens; adsorbate is re-adsorbed in the adsorbent. Adsorption heat is released (line D-A). Heat generated is called useful heat and can be transferred or used in the heating system through a heat exchanger in the adsorber [22].

\section{MASS AND ENERGY BALANCE OF ADSORPTION HEAT STORAGE}

Schematic mass balance of sorption heat storage system is presented in Fig. 3, with adsorber container to the left and the evaporator/condenser container to the right. In the desorption mode, the mass flow of the water vapor $\left(\dot{m}_{\text {vapor }}\right)$ is transferred from the adsorber to the condenser. In the adsorption mode, water vapor is transferred in the opposite direction from the evaporator to the adsorber. The condensate is evaporated and bounded with adsorber [28].

Due to the mass transfer certain properties in the control volume (dashed line) change as follows:

- the mass of water in the condenser/evaporator $(\Delta m)$,

- $\quad$ saturation of the adsorber $(\Delta x)$.

Fig. 4 schematically shows the energy balance, where some of the processes occur only during the adsorption and some of them only during desorption mode. The adsorber is heated with the heat source
$\left(Q_{D e s}\right)$. This heat is transferred through the heat exchanger to adsorbent where it is used to separate molecules of water from adsorbent and for evaporation. The water vapour entering the evaporator/condenser contains internal energy $\left(U_{v}\right)$ and heat of evaporation $\left(Q_{E}\right)$ that was needed to desorb the water from the aluminosilicate. Water vapour is condensed in the condenser. Its internal energy is discharged (i) through the heat exchanger as condensation heat $\left(Q_{C}\right)$ which could be used to preheat the sanitary water and (ii) partially through the tank walls into the surroundings as heat loss $\left(Q_{\text {Loss }}\right)$.

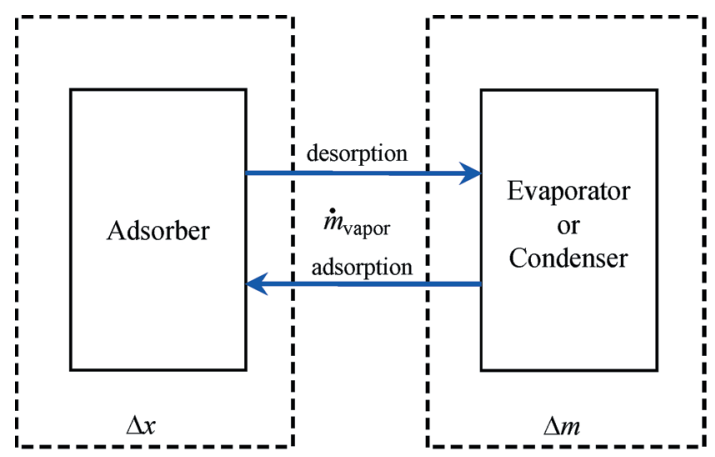

Fig. 3. Mass balance of adsorption heat storage

In adsorption mode, the evaporator is heated with the heat source $\left(Q_{A d s}\right)$. Heat input is on a lower temperature level than $Q_{\text {Des. }}$. The heat vaporizes the condensate; chemical reaction forms molecular bonds between water vapor and adsorbent. Water vapour molecules convert its kinetic energy into thermal energy to form the adsorption heat. Most of the adsorption heat $\left(Q_{A d s}\right)$ was drained out through a heat exchanger, the rest represents heat loss into surroundings through the tank walls $\left(Q_{\text {Loss }}\right)$.

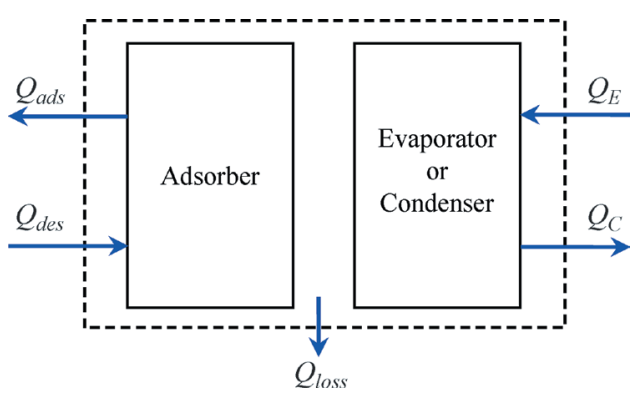

Fig. 4. Energy balance of adsorption heat storage

The energy balance based on Fig. 4 can be written as:

$$
Q_{\text {Des }}+Q_{E}-Q_{A d s}-Q_{C}-Q_{\text {Loss }}=0 .
$$




\section{PRINCIPLE OF THE OPERATION}

The heat produced by solar collector is stored in adsorption heat storage and later used for house heating. The system is designed so that it can be connected to a heating or a solar cycle. Sorption system is cyclical, which means that in the summer time tank is being charged and discharged in the winter. Scheme of closed system for residential house heating with an adsorption storage tank and the main parts of this system is shown in the Fig. 5.

The scheme on Fig. 5 shows the solar collector, the adsorption heat reservoir, the heating system and the low temperature source of energy. Some elements operate only in the summer time regime and others in the winter. When it is sunny and warm and the level of solar radiation is highest (up to $900 \mathrm{~W} / \mathrm{m}^{2}$ ), the water passing through the solar collector heats up. Solar collector used for heating buildings and sanitary hot water is medium temperature system converting solar radiation into heat. This system works in the range from 45 to $120{ }^{\circ} \mathrm{C}$ [29]. Heated water comes through the valve for winter/summer arrangement into sorption tank and is led from here to the adsorber, wherein the adsorbent is moisturized.

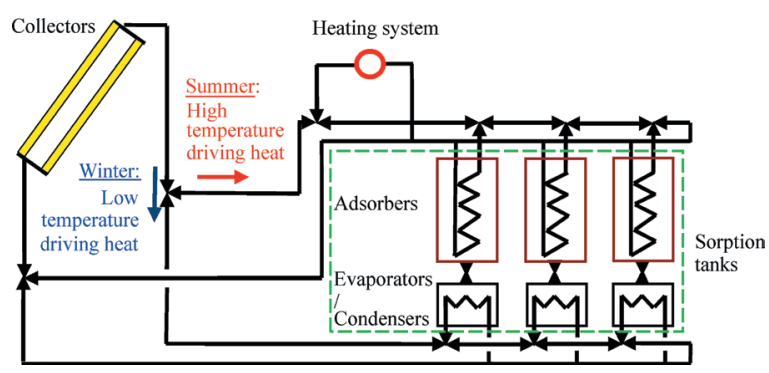

Fig. 5. System concept of the sorption reservoir for solar heating

The water releases the heat through the heat exchanger and the dry adsorbent. Water returning from the heat exchanger is cooled and is led into the collector. Described circle is called the primary circuit. In the secondary circuit, due to the heating of adsorbent with hot water, adsorbate separates and is led to the evaporator/compensator where it condensates. If the released heat during condensation is at a sufficiently high temperature level it can be used for example to preheat domestic hot water. Condensate, which is collected in the evaporator/ condenser, is separated from the adsorbent with valve (depending on the design). Once the adsorbent is dried, the phase of charging the storage ends. Usually, the discharge phase begins when the temperature of the surroundings is sufficiently low and building heating is required. Then the valve for winter/summer regime is moved to the winter circuit. Again, we have a primary and a secondary circuit. In the primary circuit water in the evaporator/condenser is evaporated with the heat from solar collector.

During the cold weather, as often in winter, the collector does not get sufficient energy and additional energy source, which acts as a reserve, is needed. These can be electric heaters or heat pumps. Heated water is led into an evaporator/condenser and condensate is evaporated through the heat exchanger. Cooled water from the evaporator/condenser returns to the solar energy collector or to the additional source. In the secondary circuit, the valve between the adsorber and the evaporator/condenser is open and water vapour is bound to the adsorbent, chemical reaction occurs and begins to release heat. Thus formed adsorption heat warms up the water in heat exchanger. From here, the heated water is led to the water heating system (i.g. radiators, pipes for floor heating). Adsorption heat can be used until the adsorbent is moistened to a certain degree. When moistened, the tank is empty and we switch to the next container (depending on model).

\section{EXPERIMENTAL STUDY}

Inspiration for the tank design came from the sketch of the tank that has been published in the report of the European project Modular high energy density sorption heat storage (MODESTORE) [5]. This is the second generation of the storage tank, which differs from the first mainly in the fact that the adsorber and the evaporator/condenser are in a single container. It is shown in Fig. 6.

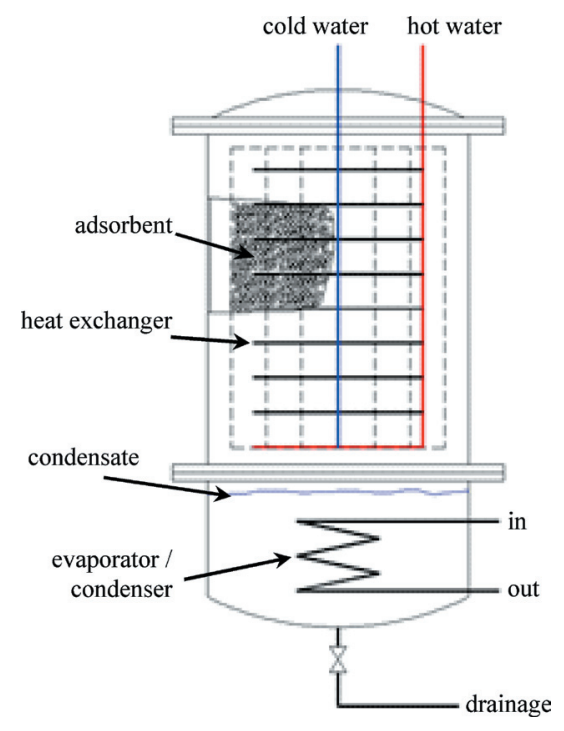

Fig. 6. Sorption thermal storage tank 
Adsorbent as material was meant as polydispersed system, formed of granules in diameter from 1 to $5 \mathrm{~mm}$, Fig. 7. Chemical name is 'sodium aluminosilicate adsorbent' with chemical formulae $\mathrm{Na}_{2} \mathrm{O} \mathrm{Al} \mathrm{O}_{3} * 2 \mathrm{SiO}_{2}$. The colour of the adsorbent is a greyish white, the bulk density of $323 \mathrm{~kg} / \mathrm{m}^{3}$ and the molecular weight of $365 \mathrm{~kg} / \mathrm{kmol}$.

The heat exchanger has two vertical copper tubes $(10 \mathrm{~mm})$ and eight horizontal tubes $(8 \mathrm{~mm})$. The vertical tubes are sealed at the bottom with two copper pins. Height of the vertical pipe is $600 \mathrm{~mm}$. The length of the horizontal tube is $1430 \mathrm{~mm}$. The pipes are at an interval of $50 \mathrm{~mm}$. For the manufacture of the basket for the adsorbent two pieces of expanded (pitting) copper plate dimensions with holes $0.5 \mathrm{~mm}$ was used.

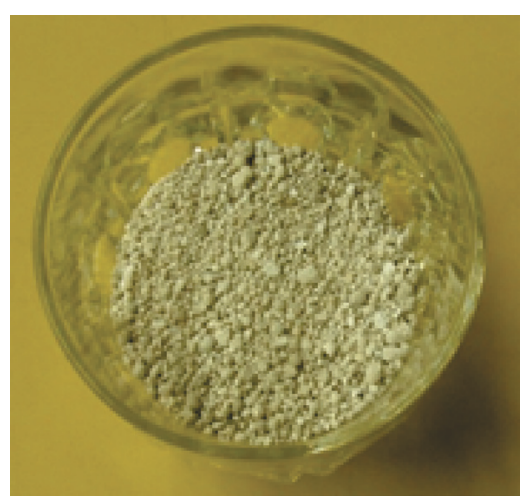

Fig. 7. Photo of aluminosilicate $H x-13$

In Fig. 8a the front view of evaporator/condenser and interior of the tank with electric heater (Fig. 8b) is shown. Further, heat exchanger with adsorbent basket (Fig. 9a) and whole for water supply (Fig. 9b) are presented in Fig. 9.
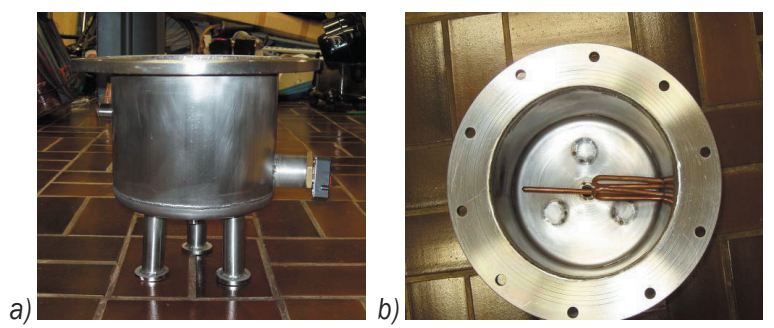

Fig. 8. a) Evaporator/condenser; and b) top view flange and electric heater

In our experiment the behaviour of the adsorption tank (Fig. 10), during the charging and discharging was observed. Fig. 11 presents the measuring line during the adsorption/desorption process where the inlet and outlet water temperature, the adsorbent temperature and water temperature were measured. Temperature sensors were placed on certain locations (no. 1, 2, 3, 4) and connected to the data acquisition device.
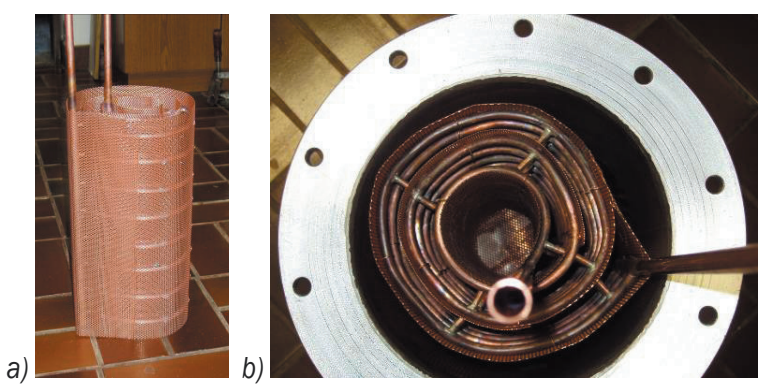

Fig. 9. a) Heat exchanger with basket; and b) top view of the heat exchanger in the tank

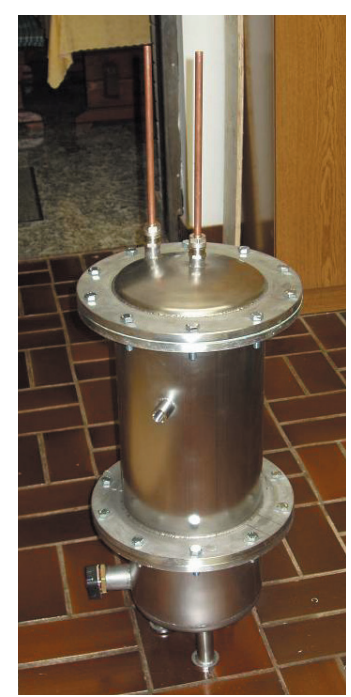

Fig. 10. Heat storage tank

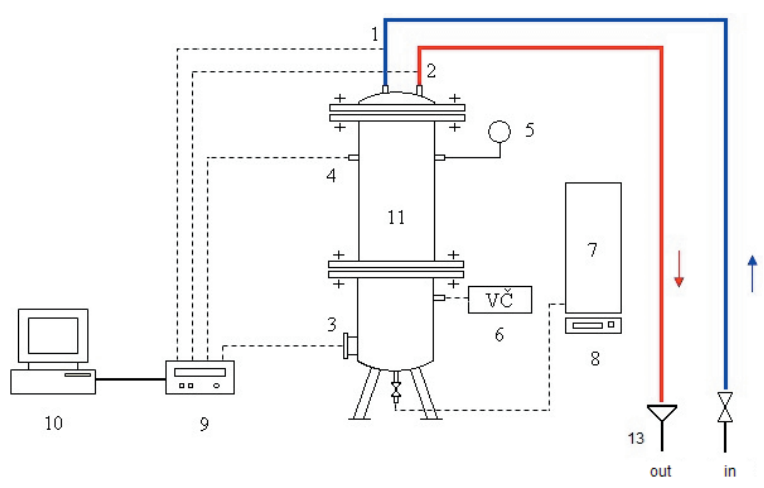

Fig. 11. Heat exchanger and the measuring instruments

Agilent 34970 (9), measured temperatures were further processed with personal computer (10). Working pressure of the adsorption was found to be between 20 and 60 mbar absolute, which means that it was necessary to vacuumize the heat exchanger first. In order to establish the required pressure condition 
in the reservoir, vacuum pump (6) and manometer (5) were used. Water was pumped from the reservoir. The water coming from the heat exchanger (11) was conveyed into drains (13). The water container (7) was placed on the balance (8) which enabled measuring of precise (exact) quantity of injected water in the evaporator. For the process of desorption, instantaneous water heater (12) was installed in order to enable hot water.

At the time of charging and discharging the tank, Agilent 34970 was collecting the following parameters:

- time - used PC internal clock,

- inlet temperature of the water (1) in the heat exchanger (11),

- outlet temperature of the water (2) from the heat exchanger (11),

- the temperature (3) in the evaporator/condenser (14) and

- the temperature in the adsorber or the temperature of the adsorbent (4).

The temperature was measured with $\mathrm{NiCr}-\mathrm{Ni}$ (Type K) temperature sensors, which were calibrated by standard procedure. Uncertainty of temperature measurement was found $0.4 \%$. Pressure was measured with manometer with the uncertainty $1.6 \%$. Mass flow rate was determined by weighting the mass in a given time interval and was found to be $5.1 \mathrm{~kg} / \mathrm{h}$. The uncertainty of the mass flow was $1.2 \%$. By the heat flux calculus a temperature dependant specific heat $c(T)$ was considered. The combined relative uncertainty of the heat flux of adsorption was found to be $1.8 \%$.

\section{RESULTS AND DISCUSSION}

\subsection{Adsorption}

In pursuit of the measurement of the adsorption phase (discharging tank), it was necessary to dry out the tank interior first. Then $5700 \mathrm{~g}$ of dry aluminosilicateHX13 was put into the adsorbent basket. After the tank was properly assembled and sealed, vacuum pump sucked air from the tank to 20 mbar of absolute pressure. Water mass flow through the heat exchanger was set to $5124 \mathrm{~g} / \mathrm{h}$ at temperature of $22{ }^{\circ} \mathrm{C}$ (Fig. 12). Agilent 34970 started with measurements of temperatures in duration of $24 \mathrm{~h}$.

As seen in Fig. 13, when the valve for dispensing the water opened, water in tank evaporated and was adsorbed on the surface of the adsorbent. As consequence, the temperature of the adsorbent has rapidly (after $3 \mathrm{~min}$ and $15 \mathrm{~s}$ ) risen up to $50{ }^{\circ} \mathrm{C}$ and soon reached maximum at $54.9^{\circ} \mathrm{C}$. As seen in Fig. 13, when the valve for dispensing the water opened, water in tank evaporated and was adsorbed on the surface of the adsorbent.

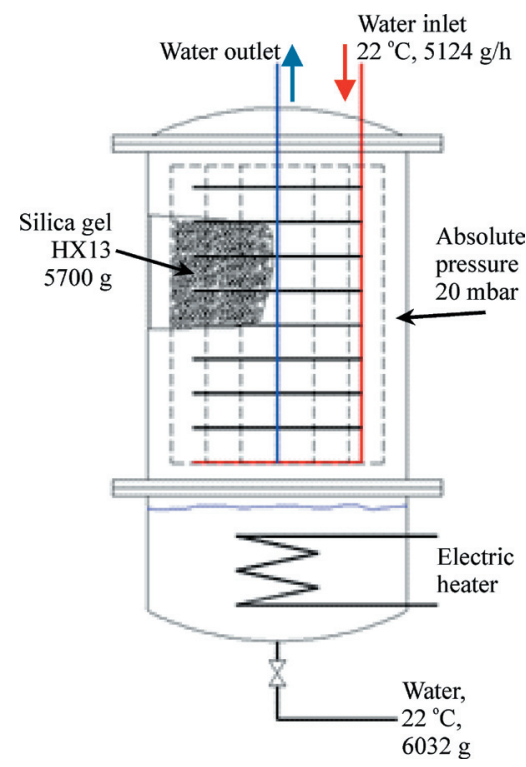

Fig. 12. Heat storage tank

As consequence, the temperature of the adsorbent has rapidly (after $3 \mathrm{~min}$ and $15 \mathrm{~s}$ ) risen up to 50 ${ }^{\circ} \mathrm{C}$ and soon reached maximum at $54.9{ }^{\circ} \mathrm{C}$. Later, the temperature of the adsorbent was gradually decreasing, probably due to the degree of saturation of the adsorbent. The temperature of the adsorbent reached a common point with the temperature of the water flowing from the heat exchanger after about three hours. The situation after this point is maintained until the end of measurement. The temperature of the adsorbent is lowered to $23.1{ }^{\circ} \mathrm{C}$, which means that the water vapor remained adsorbed, but in very small quantities. The difference between the entry of water into the exchanger, and the adsorbent after $24 \mathrm{~h}$ was $1.3{ }^{\circ} \mathrm{C}$.

The temperature of the water which was entering the heat exchanger was practically constant throughout the measurement. The temperature of the water leaving the heat exchanger was, as expected, gradually increased, primarily as a result of adsorption heat, which was transferred through a pipe of heat exchanger. Maximum temperature $43.1{ }^{\circ} \mathrm{C}$ was achieved after $22 \mathrm{~min}$ and $45 \mathrm{~s}$. Due to a temperature drop of the adsorbent, the amount of heat transferred was less than at the beginning. Therefore the water temperature at the exit from the exchanger is lowered. The downward trend curve is maintained until the end of the measurement. 


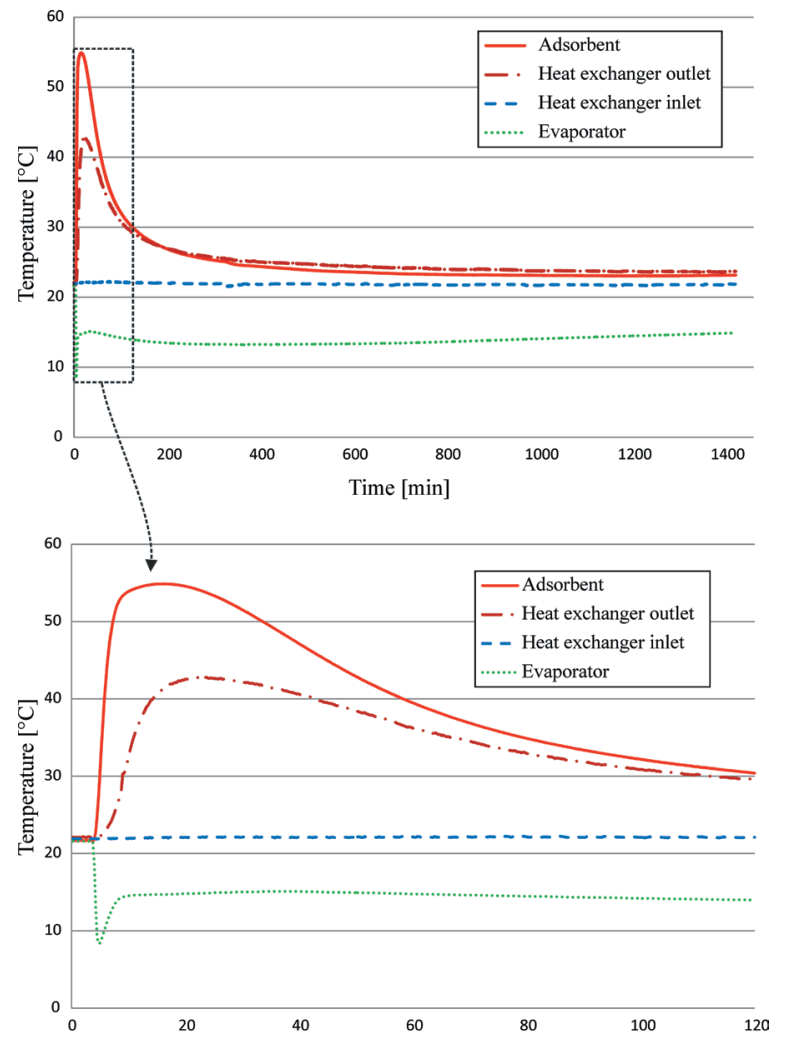

Fig. 13. Temperature change during adsorption mode

From the curve, which shows the temperature of the water in the evaporator, it can be seen that the temperature of the water very quickly fell to $8.3{ }^{\circ} \mathrm{C}$ which is the minimum. Soon after this bending point occurs, the temperature quickly rises to $14.5^{\circ} \mathrm{C}$ and then to the end of measurements varies between 13 and $15^{\circ} \mathrm{C}$. The rapid temperature drop in the beginning was probably due to intensive evaporation. When the water is evaporated at such a low temperature, its inner energy is used and that lowers the water temperature in the evaporator. Due to establishing a steady state in the container after intensive evaporation of the water, bending occurs. At a temperature of $14.5{ }^{\circ} \mathrm{C}$ this variation was stabilized and varied with the difference of $2{ }^{\circ} \mathrm{C}$ until the end of measurement.

Using the obtained data and Eq. (2):

$$
\dot{Q}_{i}=\dot{m}_{i} \cdot c_{p, i} \cdot \Delta T_{i},
$$

the instantaneous heat flow is shown in Fig. 14 shows that heat flux increased proportionally with the increase temperature of the water leaving the heat exchanger. The maximum heat flux $123 \mathrm{~W}$ was reached at the maximum temperature difference $(\Delta T)$ between the water inlet $\left(T_{e x, i}\right)$ and outlet $\left(T_{e x, o}\right)$ of the heat exchanger. After this point, the heat flux started to fall all the way to the end of the measurement.

At the end of the measurement heat flux $0 \mathrm{~W}$ should be obtained, but because of temperature settings which shuted-off after $24 \mathrm{~h}$, the temperature difference between the inlet and outlet of the water in the heat exchanger was still showing some minimal $\Delta T$. The average heat flow was found to be $21.8 \mathrm{~W}$.

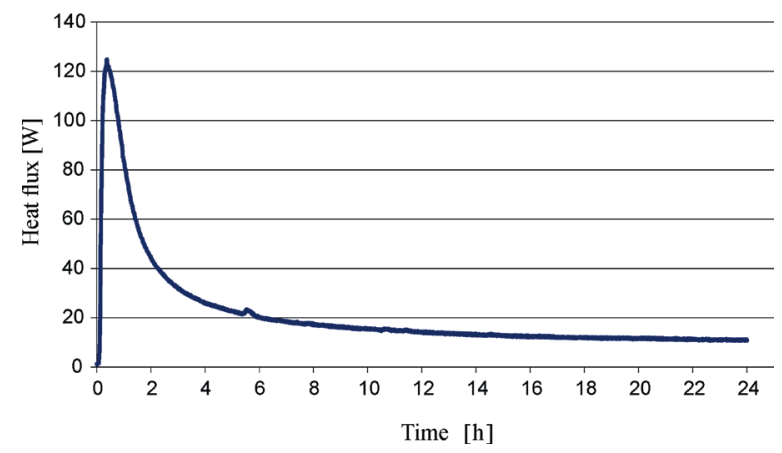

Fig. 14. Heat flux from heat exchanger

Heat flow multiplied by the time gives the heat obtained. Instantaneous heat flow was multiplied with duration of $\Delta t=15 \mathrm{~s}$ according to Eq. (3):

$$
Q_{i}=\dot{Q}_{i} \cdot \Delta t
$$

The total heat from the tank represents the sum of $Q_{i}$ according to Eq. (4) for the observed time steps, where final time step is $n=5760$.

$$
Q_{\text {total }}=\sum_{i}^{n} Q_{i} \text {. }
$$

The resulting total heat as a function of time is depicted in Fig. 15.

As can be seen from the gradient $\mathrm{d} Q / \mathrm{d} t$ the most of the heat was obtained at the beginning. After about 1.5 hour the gradient started to decrease gradually. In a 24 hours period the tank managed to transfer the total heat of $1.83 \mathrm{MJ}$ or $0.508 \mathrm{kWh}$. The specific heat/ volume is according to volume of the heat exchanger $\left(0.0104 \mathrm{~m}^{3}\right)$ equal to $48.9 \mathrm{kWh} / \mathrm{m}^{3}$.

According to work [6] testing the ability of energy storage in latent and sensible heat exchanger (at an initial temperature difference of $40^{\circ} \mathrm{C}$ between the inlet and the outlet of the storage tank) showed the following results:

- latent heat storage, $63 \mathrm{kWh} / \mathrm{m}^{3}$ and

- water sensible heat storage, $52 \mathrm{kWh} / \mathrm{m}^{3}$.

As can be seen the adsorption heat storage fall into the class of water sensible heat storage, but it is a bit better, also according to data found in $\mathrm{Yu}$ et al. [8] where similar results with aluminosilicate can be 
found (i) type $\mathrm{SG}-127 \mathrm{~B}=24.9 \mathrm{kWh} / \mathrm{m}^{3}$ and (ii) type SG-LE32 $=14.9 \mathrm{kWh} / \mathrm{m}^{3}$.

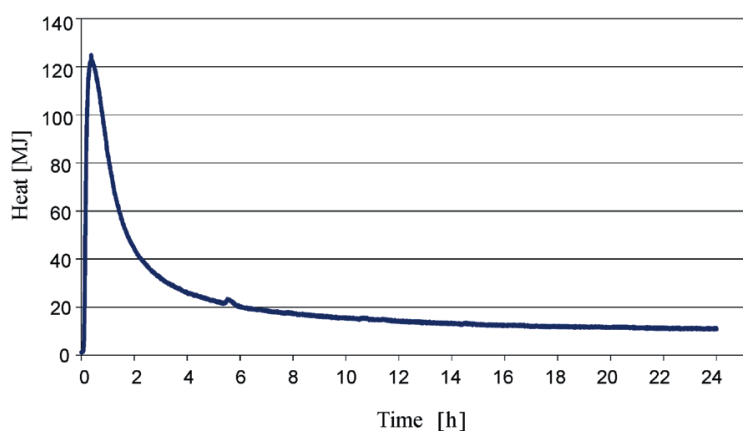

Fig. 15. Heat from the heat exchanger

There are several reasons that we must take into consideration. One of the most influential reasons is ability of adsorber to adsorb water vapour. Adsorption heat decrease with the degree of saturation of the adsorbent and therefore is lower. Adsorbent which was used was probably not developed for heat storage purpose, so to achieve better results of adsorption mode another adsorber with higher adsorption properties should be used, developed in last two or three years.

So, due to its low energy density using the aluminosilicate HX-13 in closed sorption thermal storage systems is not competitive for short-term applications; but when it used for longer period storage, aluminosilicate still possesses the heat storage ability in same extent and its energy density could be higher than sensible storage of water.

\subsection{Desorption}

In desorption mode, it was necessary to dry out the adsorbent. For this purpose the incoming water to the heat exchanger was heated to a higher temperature level. Water mass flow was $41.7 \mathrm{~kg} / \mathrm{h}$ at temperature $92.7^{\circ} \mathrm{C}$, the main parameters were measured 72 hours.

Fig. 16 shows the changes in temperature as a function of time. Strong temperature fluctuations can be seen at the beginning of the measurement due to unsteady flow and unsteady heating. Later, temperature stayed still at $95{ }^{\circ} \mathrm{C}$. As expected, the temperature got closer to the inlet temperature, and was then stabilized at a certain $\Delta T$ related to the inlet temperature, until the heating was turned off. The temperature of the heat sink should be equated with the inlet, but did not because the temperature sensors have not been calibrated to such a high temperature and therefore exhibit a certain error. Rapid fall of inlet temperature was caused with late valve closing.
Later, temperatures got closer to temperature of surroundings. The temperature of the adsorber and adsorbent temperature was increasing quite rapidly and reached maximum at the $85^{\circ} \mathrm{C}$. This temperature was maintained until the heating was stopped (after 4 hours) and then slowly falling to the ambient temperature. Adsorbent cooled down much more slowly than the water in the heat exchanger, probably because the adsorbent was in a vacuum, which served as an insulator. After the desorption mode, the adsorption mode should start again, but the pressure in the tank increased from the initial 20 to 100 mbar of absolute pressure.

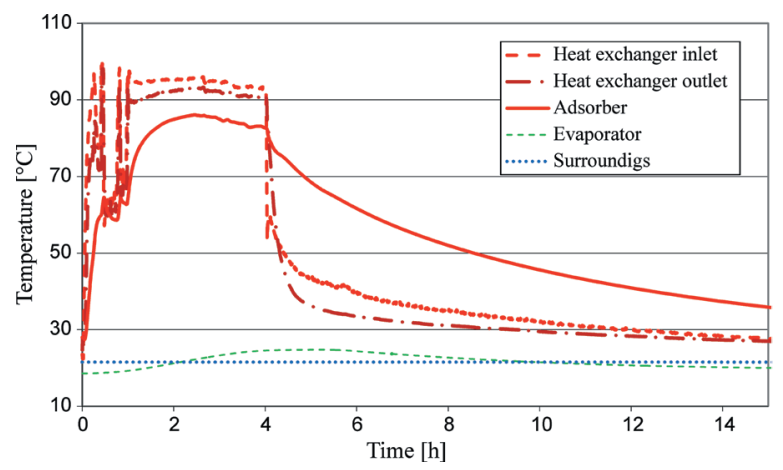

Fig. 16. Temperature change during desorption mode

The results of desorption was evaluated by weighting of removed moisture from the adsorbent. The tank drained $4758 \mathrm{~g}$ of water. The mass of dry adsorbent was known, moistened mass also, so the difference was $1150 \mathrm{~g}$ of water in the adsorbent. Summing these two masses gives $5908 \mathrm{~g}$ of water in the tank after both (two) modes. This result should be matched with the mass of water which has been dosed at the start of measurement (6032 g), but it does not. The mass difference of $124 \mathrm{~g}$ probably remained on the tank and bottom walls. The temperature during both weighing was the same $\left(21.5^{\circ} \mathrm{C}\right)$. The mass difference was $2 \%$, which is acceptable. From the measured data it is now possible to determine the level of moisture in the adsorbent. Assuming that the adsorbent was completely dry at the beginning, results show that the adsorbent contained about $20.2 \%$ moisture after the desorption, so minimal or almost no adsorbed water vapour was desorbed in the desorption. This probably happened because during the process of desorption, walls of the tank should be cooled in order to carry out intensive condensation. The results would be even better if the water in condenser was cooled.

Another very important feature is the fact that a vacuum and adsorbent inside the tank are both 
insulators. Heat transfer from the heat exchanger to the adsorbent was most likely due to attenuation only at the junction and elsewhere already negligible, therefore the water was evaporated from only a small part of the adsorbent. We can achieve very good results by a slightly different design of the heat exchanger, where the emphasis would be right at the interfaces of the heat exchanger and the adsorbent.

\section{CONCLUSIONS}

For efficient utilization of solar heat energy, compact and cost effective seasonal thermal storage systems are essential. One of the options is to use sorption heat storage principle. Heat storage tank with aluminosilicate HX-13 as adsorbent has been designed. This material is a product of Slovenian company.

As for the construction, there were a lot of challenges with the under-pressure in the tank which were successfully exceed, but it should be noted that in the implementation of further attempts is to avoid sealing tape, which has proved to be inefficient when it is necessary to keep a vacuum in a container for several days.

However, it should be noted that the results of the adsorption mode would be better if the basket would be totally spilled with an adsorbent. Because of the absence of the adsorbent, the other two tubes of heat exchanger were revealed, which means that during the adsorption mode the water vapor raised above the basket with revealed tubes, and cooled water in them.

As a result, the temperature of the water at the exit from the heat exchanger was lower, with maximum $43.1{ }^{\circ} \mathrm{C}$ and was than lowering until the end of the measurement to approximately $25^{\circ} \mathrm{C}$. Consequently, the resulting heat generated from the heat storage was lower.

It was demonstrated that the adsorption heat storage tank actually works in practice. In $24 \mathrm{~h}$ the heat from the heat exchanger was 1.8 MJ. In addition, it has one outstanding characteristic - heat can remain stored in the tank as long as adsorbent and adsorbate are separated and this is a huge advantage over sensible and latent heat storage.

\section{NOMENCLATURE}

$\begin{array}{ll}c_{p} & \text { specific heat }[\mathrm{J} / \mathrm{kgK}] \\ \Delta m & \text { mass change }[\mathrm{kg}] \\ \dot{m} & \text { mass flow }[\mathrm{kg} / \mathrm{s}] \\ \dot{m}_{\text {vapor }} & \text { vapor mass flow }[\mathrm{kg} / \mathrm{s}] \\ p_{c} & \text { condensation pressure }[\mathrm{Pa}]\end{array}$

$p_{e} \quad$ evaporation pressure $[\mathrm{Pa}]$

$Q_{A d s} \quad$ adsorption heat [J]

$Q_{\text {Des }} \quad$ desorption heat [J]

$Q_{C} \quad$ condensation heat [J]

$Q_{E} \quad$ evaporation heat [J]

$Q_{i} \quad$ heat of individual point [J]

$Q_{\text {Loss }}$ heat loss [J]

$Q_{\text {total }} \quad$ total heat from heat exchanger [J]

$\dot{Q} \quad$ heat flux $[\mathrm{W}]$

$\dot{Q}_{i} \quad$ heat flux of individual point [W]

$T_{A d s 1} \quad$ temperature at the beginning of adsorption $[\mathrm{K}]$

$T_{A d s 2} \quad$ temperature at the end of adsorption [K]

$T_{\text {Des1 }}$ temperature at the beginning of desorption $[\mathrm{K}]$

$T_{\text {Des2 }} \quad$ temperature at the end of desorption [K]

$T_{e x, i} \quad$ inlet temperature of heat exchanger [K]

$T_{e x, o} \quad$ outlet temperature of heat exchanger [K]

$\Delta t \quad$ time interval [s]

$\Delta T \quad$ change in temperature [K]

$U_{v} \quad$ internal energy of vapor [J]

$x_{\min } \quad$ minimal saturation $\left(\mathrm{kg}_{\text {Adsobat }} / \mathrm{kg}_{\text {Adsorben }}\right)$

$\Delta x \quad$ saturation change $\left(\mathrm{kg}_{\text {Adsobat }} / \mathrm{kg}_{\text {Adsorbent }}\right)$

WH water heater

\section{REFERENCES}

[1] Majdič, F., Bombač, A. (2014). Work efficiency of the new water hydraulic piston-type gas accumulator. Ventil, vol. 20, no. 2, p. 118-124. (in Slovene)

[2] Bombač, A., Šelih, Z. (2011). Thermodynamic analysis by sulphuric acid production in sorption tower. Ventil, vol. 17, no. 3, p. 178-184. (in Slovene)

[3] Jaehnig, D., Hausner, R., Wagner, W., Isakkson, C. (2006). Thermochemical Storage for Solar Space Heating in a Single-Family House. AEE - Institute for Sustainable Technologies, Gleisdorf.

[4] Stritih, U., Osterman, E., Evliya, H., Butala, V., Paksoy, H. (2013). Exploiting solar energy potential through thermal energy storage in Slovenia and Turkey. Renewable \& Sustainable Energy Reviews, vol. 25 p. 442-461, DOI:10.1016/j.rser.2013.04.020.

[5] Wang, D.C., Li, Y.H., Xia, Y.Z., Zhang, J.P. (2010). A review on adsorption and refrigeration technology and adsorption deterioration in physical adsorption systems. Renewable \& Sustainable Energy Reviews, vol. 14, no. 1, p. 344-353, DOI:10.1016/j.rser.2009.08.001.

[6] Stritih, U., Butala, V. (2011). Energy savings in building with a PCM free cooling system. Strojniški vestnik - Journal of Mechanical Engineering, vol. 57, no. 2, p. 125-134, DOI:10.5545/sv-jme.2010.066.

[7] Osterman, E., Tyagi, V.V., Butala, V., Rahim, N.A., Stritih, U. (2012). Review of PCM based cooling 
technologies for buildings. Energy and Buildings, vol. 49, p. 37-49, DOI:10.1016/j.enbuild.2012.03.022.

[8] Yu, N., Wang, R.Z., Wang, L.W. (2013). Sorption thermal storage for solar energy. Progress in Energy and Combustion Science, vol. 39, no.5 p. 489-514, DOI:10.1016/j.pecs.2013.05.004.

[9] Ristić, A., Maučec, D., Henninger, S.K., Kaučič, V. (2012). New two-component water sorbent $\mathrm{CaCl} 2$ FeKIL2 for solar thermal energy storage. Microporous and Mesoporous Materials, vol. 164, p. 266-272, DOI:10.1016/j.micromeso.2012.06.054.

[10] Ristić, A., Zabukovec Logar, N., Henninger, S.K., Kaučič, V. (2012). The performance of small-pore microporous aluminophosphates in low-temperature solar energy storage. Advanced Functional Materials, vol. 22, p. 1952-1957, DOI:10.1002/adfm.201102734.

[11] Hauer, A. (2007). Sorption theory for thermal energy storage. Paksoy, H.Ö. (ed.) Thermal Energy Storage for Sustainable Energy Consumption, Fundamentals, Case Studies and Design, NATO Science Series, vol. 234, p. 393-408.

[12] Wang, D.C., Li, Y.H., Li, D., Xia, Y.Z., Zhang, J.P. (2010). A review on adsorption refrigeration technology and adsorption deterioration in physical adsorption systems. Renewable and Sustainable Energy Reviews, vol. 14, no. 1, p. 344-353, DOI:10.1016/j. rser.2009.08.001.

[13] Jänchen, J., Ackermann, D., Stach, H., Broesicke, W. (2004). Studies of the water adsorption on zeolites and modified mesoporous materials for seasonal storage of solar heat. Solar Energy, vol. 76, no. 1-3, p. 339-344, DOI:10.1016/j.solener.2003.07.036.

[14] Aristov,Y.I. (2013). Challenging offers of material science for adsorption heat transformation: A review. Applied Thermal Engineering, vol. 50, no. 2, p. 16101618, DOI:10.1016/j.applthermaleng.2011.09.003.

[15] Cot-Gores, J., Castell, A., Cabeza, L.F. (2012). Thermochemical energy storage and conversion: a-state-of-the-art review of the experimental research under practical conditions. Renewable and Sustainable Energy Reviews, vol. 16, no. 7,p. 5207-5224, DOI:10.1016/j.rser.2012.04.007.

[16] Abedin, A.H., Rosen, M.A. (2012). Close and open thermochemical energy storage: energy- and exergybased comparisons. Energy, vol. 41, p. 83-92, DOI:10.1016/j.energy.2011.06.034.

[17] Restuccia, G., Freni, A., Vasta, S., Aristov, Y. (2004). Selective water sorbent for solid sorption chiller: experimental results and modelling. International Journal of Refrigeration, vol. 27, no. 3, p. 284-293, DOI:10.1016/j.ijrefrig.2003.09.003.

[18] Glaznev, I., Ponomarenko, I., Kirik, S., Aristov, Y. (2011). Composites CaCl2/SBA-15 for adsorptive transformation of low temperature heat: Pore size effect. International Journal of Refrigeration, vol. 34, no. 5 p. 1244-1250, DOI:10.1016/j.ijrefrig.2011.02.007.

[19] Critoph, R.E. (2001). Simulation of a continuous multiple-bed regenerative adsorption cycle. International Journal of Refrigeration, vol. 24, no. 5, p. 428-437, DOI:10.1016/S0140-7007(00)00026-8.

[20] Khattab, N.M. (2004). A novel solar-powered adsorption refrigeration module. Applied Thermal Engineering, vol. 24, no. 17-18, p. 2747-2760, DOI:10.1016/j.applthermaleng.2004.04.001.

[21] Ziegler, F. (2009). Sorption heat pumping technologies: Comparisons and challenges. International Journal of Refrigeration, vol. 32, no. 4, p. 566-576, DOI:10.1016/j. ijrefrig.2009.03.007.

[22] Ziegler, F. (2002). State of the art in sorption heat pumping and cooling Technologies. International Journal of Refrigeration, vol. 25, no. 4, p. 450-459, DOI:10.1016/S0140-7007(01)00036-6.

[23] Henninger, S.K., Munz, G., Ratzsch, K.-F., Schossig, P. (2011). Cycle stability of sorption materials and composites for the use in heat pumps and cooling machines. Renewable Energy, vol. 36, no. 11, p. 30433049, DOI:10.1016/j.renene.2011.03.032.

[24] Daßler, I., Mittelbach, W. (2012). Solar cooling with adsorption chillers. Energy Procedia, vol. 30, p. 921929, DOI:10.1016/j.egypro.2012.11.104.

[25] Reddy Meenakshi, R., Nallusamy, N., Prasad Anjaneya, B., Reddy Hemachandra, K. (2012). Thermal energy storage system using phase change materials: constant heat source. Thermal Science, vol. 16, no. 4, p. 1097 1104, DOI:10.2298/TSCI100520078R.

[26] Kashani S., Lakzian E. (2014). Numerical analysis of melting of nano-enhanced phase change material in latent heat thermal energy storage system. Thermal Science, vol. 18, suppl. 2, p. S335-S345, DOI:10.2298/ TSCI111212163K.

[27] Schmidt, F.P. (2004). Optimizing Adsorbents for Heat Storage Applications: Estimation of Thermodynamic Limits and Monte Carlo Simulations of Water Adsorption in Nanopores. Inaugural-Dissertation, Albert-Ludwigs-University, Faculty of Mathematics und Physics, Freiburg.

[28] Jähnig, D., Wagner, W. (2004). Monitoring and Evaluation of the $1^{\text {st }}$ Generation System Installed in Austria. Institute for Sustainable Technologies, Gleisdorf.

[29] Hug, R. (1999). Summer Sun all Winter: Seasonal Heat Reservoir covers heating needs up to $100 \%$. Solar Magazine, ISE Fraunhofer Institute for Solar Energy Systems, Freiburg im Breisgau. 